\title{
FEM modelling of deep excavation - parametric study, Hypoplastic Clay model verification
}

\author{
Monika Mitew-Czajewska ${ }^{1, *}$ \\ ${ }^{1}$ Warsaw University of Technology, Faculty of Civil Engineering, Institute of Roads and Bridges, Al. \\ Armii Ludowej 16, 00-637 Warsaw, Poland
}

\begin{abstract}
A parametric case study of a $25,5 \mathrm{~m}$ deep excavation is presented. Finite Element analysis was performed using Modified Mohr-Coulomb and Hypoplastic Clay constitutive soil models. The results of the FE analysis were compared to in-situ displacements measurements taken during construction as well as to the results of calculations made using dependent pressures method. Final conclusions concerning the applicability of the Hypoplastic Clay constitutive soil model for modelling of deep excavations made in soft clay in terms of accurate determination of horizontal displacements of the excavation wall are presented.
\end{abstract}

\section{Introduction}

The very first challenge of the numerical modelling of geotechnical or underground structures by means of Finite Element Method (FEM) is the choice of appropriate constitutive soil model. In the engineering practice the most commonly used model is Mohr-Coulomb or Modified Mohr-Coulomb model due to the simplicity and availability of its parameters. This practice is acceptable in case of simple structures and simple geotechnical conditions. While for demanding projects, e.g. very deep excavations built in complex geotechnical conditions it leads to wrong estimation of structure displacements and internal forces. In Warsaw, in locations where Mio-Pliocene clays dominate in the subsoil, the choice of constitutive soil model for FE analysis is a great challenge. Several attempts of the use of other soil models were made, such as Hardening Soil model [1], Modified Cam-Clay [2] or Hypoplastic Clay model [3] - the latter showing very promising results.

The case study presented in the paper, describing 25,5 $\mathrm{m}$ deep excavation executed in a very complex geotechnical conditions, mostly in Mio-Pliocene clays, is aimed to assess the applicability of the Hypoplastic Clay model (HC model) implemented in GEO5 FEM software [4].

\footnotetext{
*Corresponding author: m.mitew@il.pw.edu.pl
} 


\section{Description of the case}

The 25,5 $\mathrm{m}$ deep excavation for the construction of metro station was executed in a very complex geotechnical conditions (dominating Mio-Pliocene clays, and high water pressure). Cut and cover method was used for the construction of the station; the stability of $36 \mathrm{~m}$ deep diaphragm walls during excavation was ensured by 3 levels of underground slabs. Detailed description of the geometry and construction stages can be found in [5].

\subsection{Geotechnical conditions}

In general, the subsoil of Warsaw is composed of Tertiary deposits covered with a complex of Quaternary formations from the Pleistocene and Holocene periods. In the analysed case, there is a 3-5 m thick layer of fills directly under the surface, below which 6-7 $\mathrm{m}$ of fluvioglacial sands and 5-6 m glacial sandy clays occur. These layers are covering the MioPliocene deposits (clays, silty clays or stiff silty clays) expanding to great depths. In order to take into account the change in parameters with depth, clay layer is divided into two layers in the model. Detailed description of soil conditions in the analysed case is included in [5].

The main groundwater table is located $8.5 \mathrm{~m}$ below the ground surface.

Geotechnical parameters of all soil layers specified above are given in Table 1 and 2 in the numerical analysis description chapter.

\subsection{Construction stages}

The following construction stages were considered:

Stage 1 - Construction of peripheral diaphragm walls

Stage 2 - Excavation $-4.9 \mathrm{~m}$ below ground surface

Stage 3 - Construction of the roof slab of the upper station (1.2m thick)

Stage 4 - Excavation $-9.8 \mathrm{~m}$ below ground surface

Stage 5 - Construction of the first/top intermediate slab ( $0.6 \mathrm{~m}$ thick)

Stage 6 - Excavation - $17.2 \mathrm{~m}$ below ground surface

Stage 7 - Construction of the third/bottom intermediate $(0.5 \mathrm{~m}$ thick)

Stage 8 - Excavation $-25.5 \mathrm{~m}$ below ground surface

Stage 9 - Construction of the foundation slab (1.2m thick).

\section{Numerical analysis}

\subsection{Basic assumptions}

The numerical FE model was built in GEO5 FEM software. Model dimensions are 70x120m. FE model mesh, generated automatically, was built of 11933 nodes, 7016 elements (4620 surface elements, 599 beam elements, and 1797 contact elements).

The following basic assumptions were adopted in the numerical FE model:

- Final excavation depth $-25.5 \mathrm{~m}$,

- Diaphragm wall height - $36 \mathrm{~m}$, and thickness - $1.2 \mathrm{~m}$,

- 3 slabs supporting the diaphragm wall in the temporary and permanent state,

- Construction stages as specified in chapter 2.2.

The geometry of the model and the finite elements mesh are presented in Figure 1.

In addition following assumptions concerning underground water modelling were adopted in accordance with construction methods: 
- Peripheral diaphragm walls embedded in clays cut the inflow of water into the excavation,

- The water level inside the excavation was lowered in accordance with the excavation depth (in each construction stage - $1 \mathrm{~m}$ below the current excavation level).

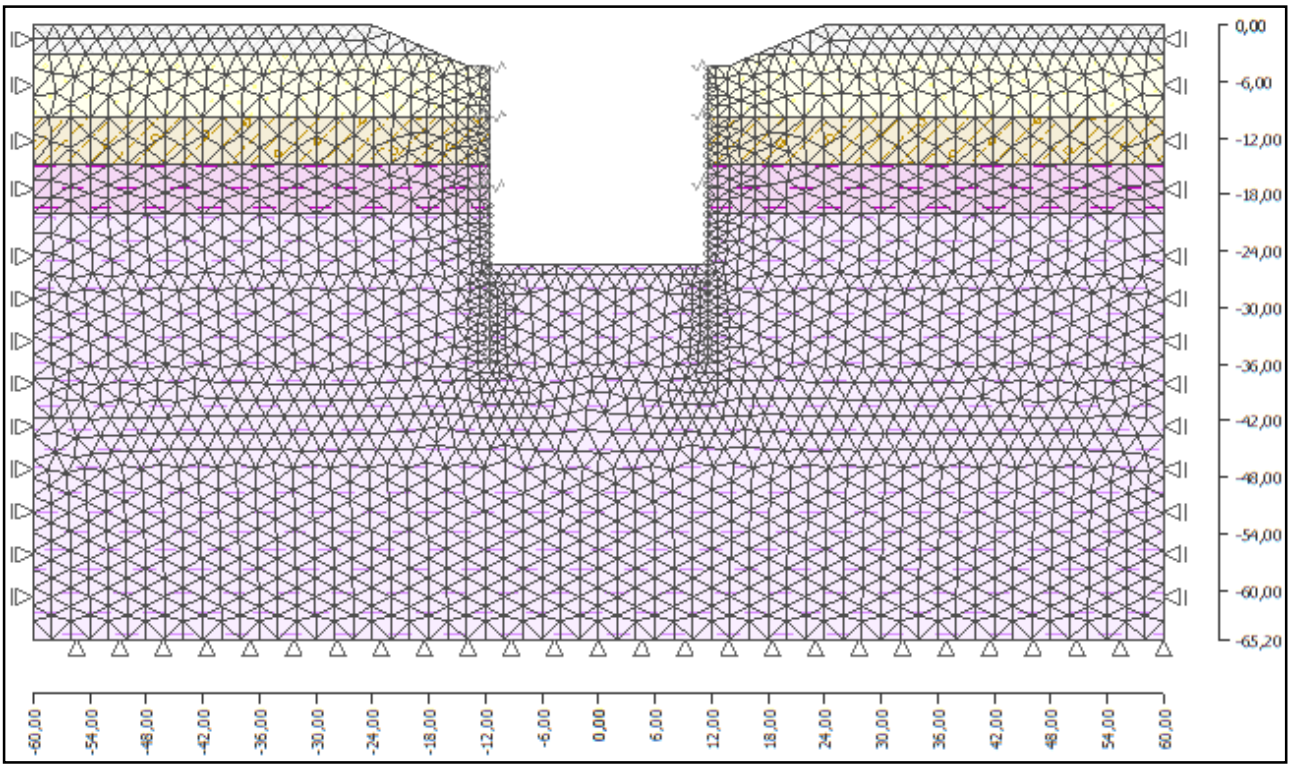

Fig. 1. The geometry of the model, FE mesh

\subsection{Constitutive soil models}

Two calculation series of the case were made with the use of following constitutive soil models: Modified Mohr-Coulomb, the formulation of which is presented in [4] and Hypoplastic Clay model. The Hypoplastic Clay model is a critical state model applicable for modelling of fine grain soft soils [4]. The model allows for reflecting a different stiffness in loading and unloading, and softening or hardening, in dependence with the soil compaction and the change of volume in shearing (dilation, compression). The state boundary of the Hypoplastic Clay model in meridian and deviatoric plane is shown on Figure 2 (left and right respectively). The mathematical formulation of the HC model is given in [6].

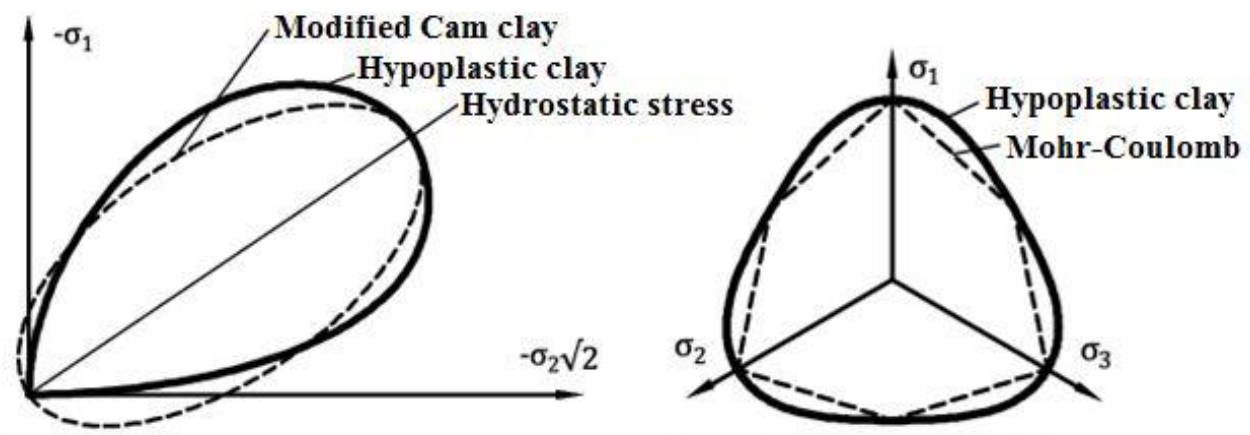

Fig. 2. State boundary of Hypoplastic Clay model: in the meridial plane (left), in the deviatoric plane (right) 


\subsection{Model parameters}

Parameters of all soil layers occurring in the numerical model applied in the analysis are compiled in Table 1 (for Modified Mohr-Coulomb model) and Table 2 (for Hypoplastic Clay model). Please note also that the Hypoplastic Clay constitutive model was applied only to the Mio-Pliocene clay layer (divided into 2 sub-layers as explained before). Fill, Sand and Sandy Clay layers were in both calculation series modelled by means of Modified Mohr-Coulomb model.

Table 1. Soil parameters - Modified Mohr-Coulomb model

\begin{tabular}{|c|c|c|c|c|c|c|}
\hline & $\gamma$ & $\varphi$, & $\mathbf{c}^{\prime}$ & $\mathbf{E}$ & Ko & v \\
\cline { 2 - 7 } & $\mathbf{k N} / \mathbf{m}^{3}$ & $\mathbf{k}$ & $\mathbf{k P a}$ & MPa & - & - \\
\hline Fill & 18 & 25 & $\mathbf{0}$ & 25 & 0.577 & 0,30 \\
\hline Sand & 19 & 34 & 0 & 50 & 0.441 & 0,30 \\
\hline $\begin{array}{c}\text { Sandy } \\
\text { Clay }\end{array}$ & 21 & 31 & 3 & 50 & 0.485 & 0,29 \\
\hline Clay 1 & 20 & 18 & 10 & 80 & 0.917 & 0,35 \\
\hline Clay 2 & 21 & 18 & 15 & 100 & 0.783 & 20 \\
\hline
\end{tabular}

Table 2. Soil parameters - Hypoplastic Clay model

\begin{tabular}{|c|c|c|c|c|c|c|c|c|}
\hline & $\gamma$ & $K o$ & $\kappa$ & $\lambda$ & $\mathrm{e}_{0}$ & $\mathrm{e}_{\max }$ & $\varphi_{\mathrm{cv}}$ & $\mathrm{r}$ \\
\cline { 2 - 8 } & $\mathrm{kN} / \mathrm{m}^{3}$ & - & - & - & - & - & 0 & - \\
\hline Clay 1 & 20 & 0.917 & 0.019 & 0.071 & 0.57 & 2.5 & 13 & 0,5 \\
\hline Clay 2 & 21 & 0.783 & 0.019 & 0.071 & 0.57 & 2.5 & 13 & 0,5 \\
\hline
\end{tabular}

All parameters except $\mathrm{e}_{\max }, \varphi_{\mathrm{cv}}$ and $\mathrm{r}$ for the $\mathrm{HC}$ model where established based on laboratory and field tests carried out at the Department of Geotechnics and Underground Structures of the Warsaw University of Technology $[2,7,8]$. Parameters $e_{\max }, \varphi_{c v}$ and $r$ were taken as average for similar soil types [4]. Precise specification of all parameters of the Hypoplastic Clay model for Mio-Pliocene clays is a part of ongoing study.

\subsection{Results of FE analysis}

The results of calculation series in form of plots of the horizontal displacements fields in the final excavation stage, including graphs of horizontal diaphragm walls displacements are presented on Figure 3 and Figure 4 for Modified Mohr-Coulomb and Hypoplastic Clay models respectively. The maximum theoretical value of horizontal wall displacement obtained using MMC model is $30.6 \mathrm{~mm}$, and $\mathrm{HC}$ model $-13.6 \mathrm{~mm}$, while the maximum displacement measured during construction was $15.6 \mathrm{~mm}$. This indicates that the Hypoplastic Clay model can be found valuable for modelling of Mio-Pliocene soft clays. 


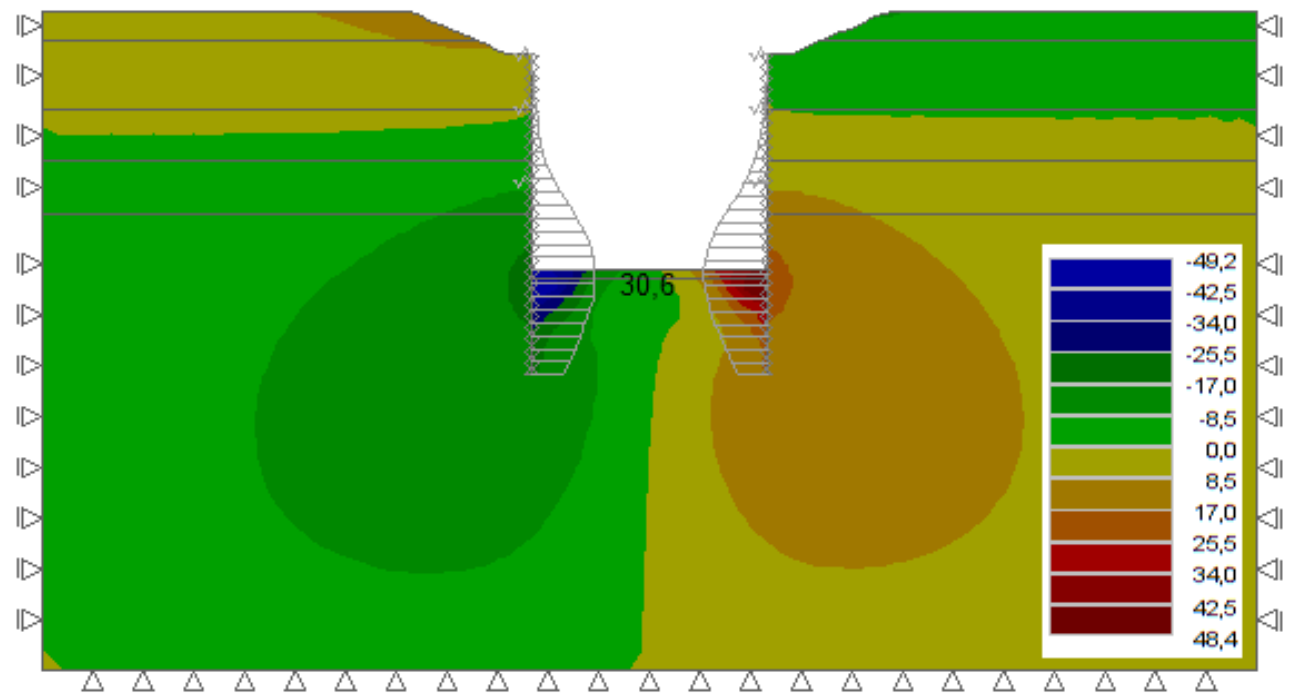

Fig. 3. Results of FE analysis, Modified Mohr-Coulomb model, horizontal displacements plot in final excavation stage

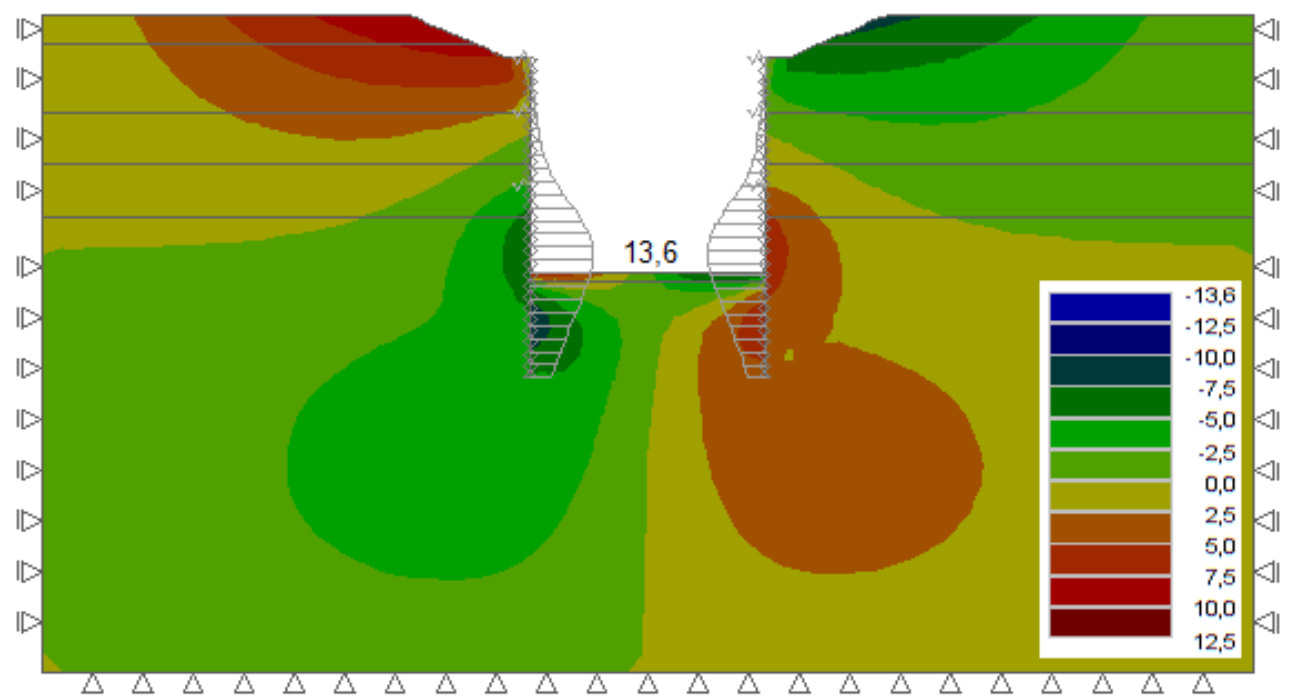

Fig. 4. Results of FE analysis, Hypoplastic Clay model, horizontal displacements plot in final excavation stage

\section{Summary and conclusions}

The Mio-Pliocene clay occurring on the large area of central Poland is a very difficult material to model in FE analysis. The use of Modified Mohr-Coulomb constitutive model, with simple and easily available model parameters, for this material usually leads to missestimation of displacements of the excavation wall (Fig. 5). In the paper, the attempt of application of Hypoplastic Clay constitutive model for modelling of Mio-Pliocene clay is presented. The comparison of maximum theoretical horizontal displacements of the excavation wall calculated using Modified Mohr-Coulomb (MMC) and Hypoplastic Clay 
(HC) models with real wall displacements measured during construction is presented on Figure 5. In addition, reference result of the calculation of wall displacement using dependent pressures method is shown, based on [5]. It may be observed that Hypoplastic Clay model is suitable for modelling of deep excavations in Mio-Pliocene clays. The key issue is the proper calibration of model parameters. Further tests and studies will be made in this field.

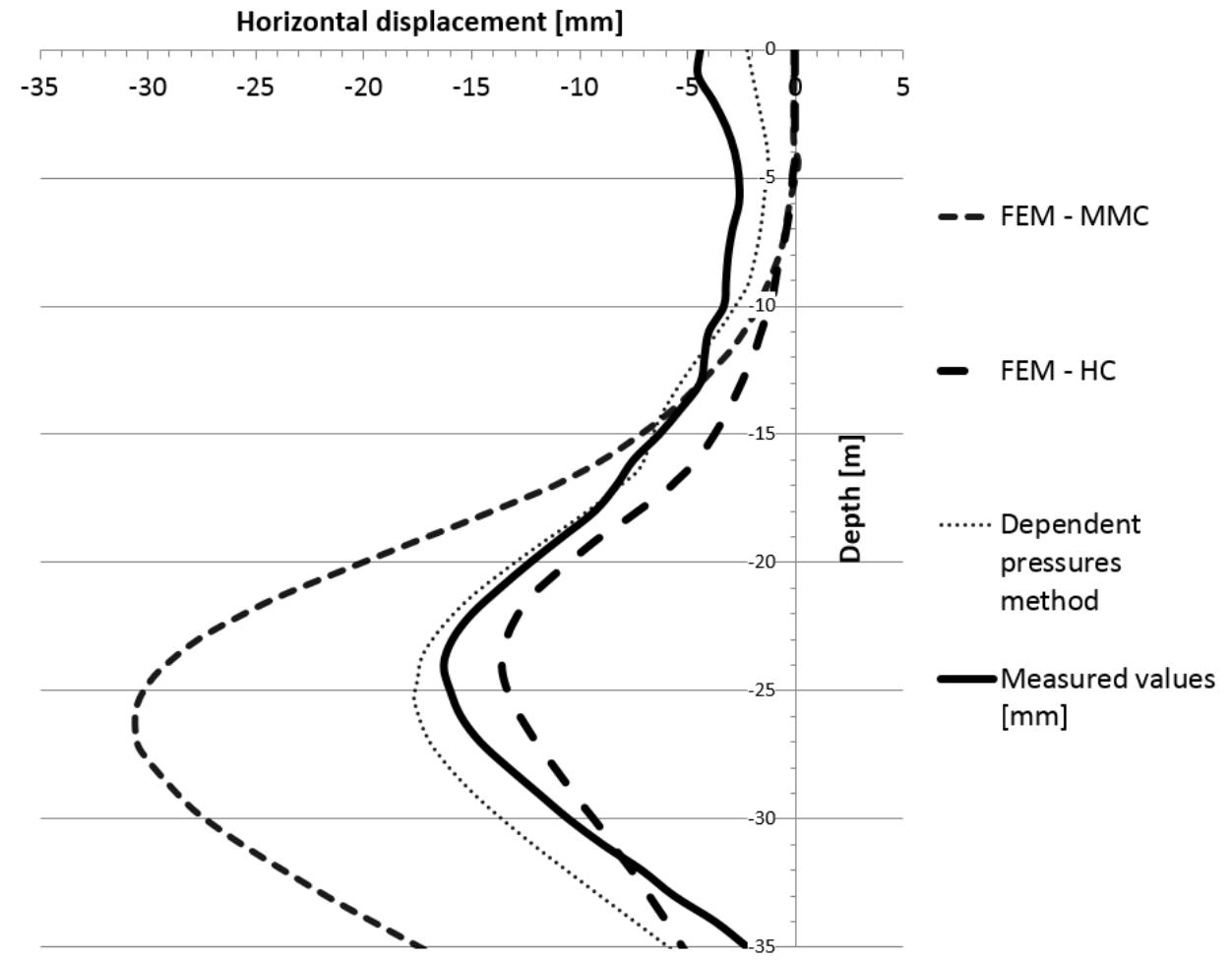

Fig. 5. Comparison of diaphragm wall maximum horizontal displacements

\section{References}

1. A. Truty, R. Obrzud, Studia Geotechnica et Mechanica, 37, 61 (2015)

2. M. Superczyńska, K. Józefiak, A. Zbiciak, ACE 62(3), 207 (2016)

3. M. Mitew-Czajewska, ACE 62(4), 73 (2016)

4. Fine Ltd, GEO5 User Guide (Prague, 2017)

5. M. Mitew-Czajewska, Geotechnical Aspects of Underground Construction in Soft Ground (CRC Press, 2014)

6. D. Mašín, International Journal for Numerical and Analytical Methods in Geomechanics 29(4), 311 (2005)

7. R. Kuszyk, M. Superczyńska, A. Lejzerowicz, Przegląd Komunikacyjny 9, 59 (2012) In polish

8. M. Superczyńska, Geologiczno-inżynierska ocena iłów formacji poznańskiej jako podłoża budowlanego (PHD thesis, Warsaw University of Technology, 2015) In polish

9. A.Z. Ter-Martirosyan, Z.G. Ter-Martirosyan, Procedia Engineering, 111, 756 (2015)

10. Z.G. Ter-Martirosyan, A.Z. Ter-Martirosyan, Soil Mech Found Eng 51, 273 (2015) 